$\underline{\text { Iranian Journal of Pathology | ISSN: 2345-3656 }}$

\title{
Clinical Manifestations and Diagnosis of Nonalcoholic Fatty Liver Disease
}

\author{
Mahmoodreza Khoonsari', Mohammadreza Mohammad Hosseini Azar', Ramak Ghavam', \\ Khadijeh Hatami ${ }^{2}$, Mosa Asobar ${ }^{1}$,Ali Gholami ${ }^{3,4}$, Abdolhalim Rajabi ${ }^{5}$, Fahimeh Safarnezhad \\ Tameshkel $^{1}$, Bahare Amirkalali ${ }^{1}$, Masoudreza Sohrabi ${ }^{1 *}$. \\ 1. Gastrointestinal and Liver Disease Research Center, Iran University of Medical Sciences, Tehran, Iran \\ 2. Faculty of Iranian Traditional Medical, Tehran University of Medical Sciences \\ 3. Dept. of Public Health, School of Public Health, Neyshabur University of Medical Sciences, Neyshabur, Iran \\ 4. Dept. of Epidemiology, School of Public health, Iran university of medical sciences ,Tehran, Iran \\ 5. Zabol University of Medical Sciences, Zabol, Iran
}

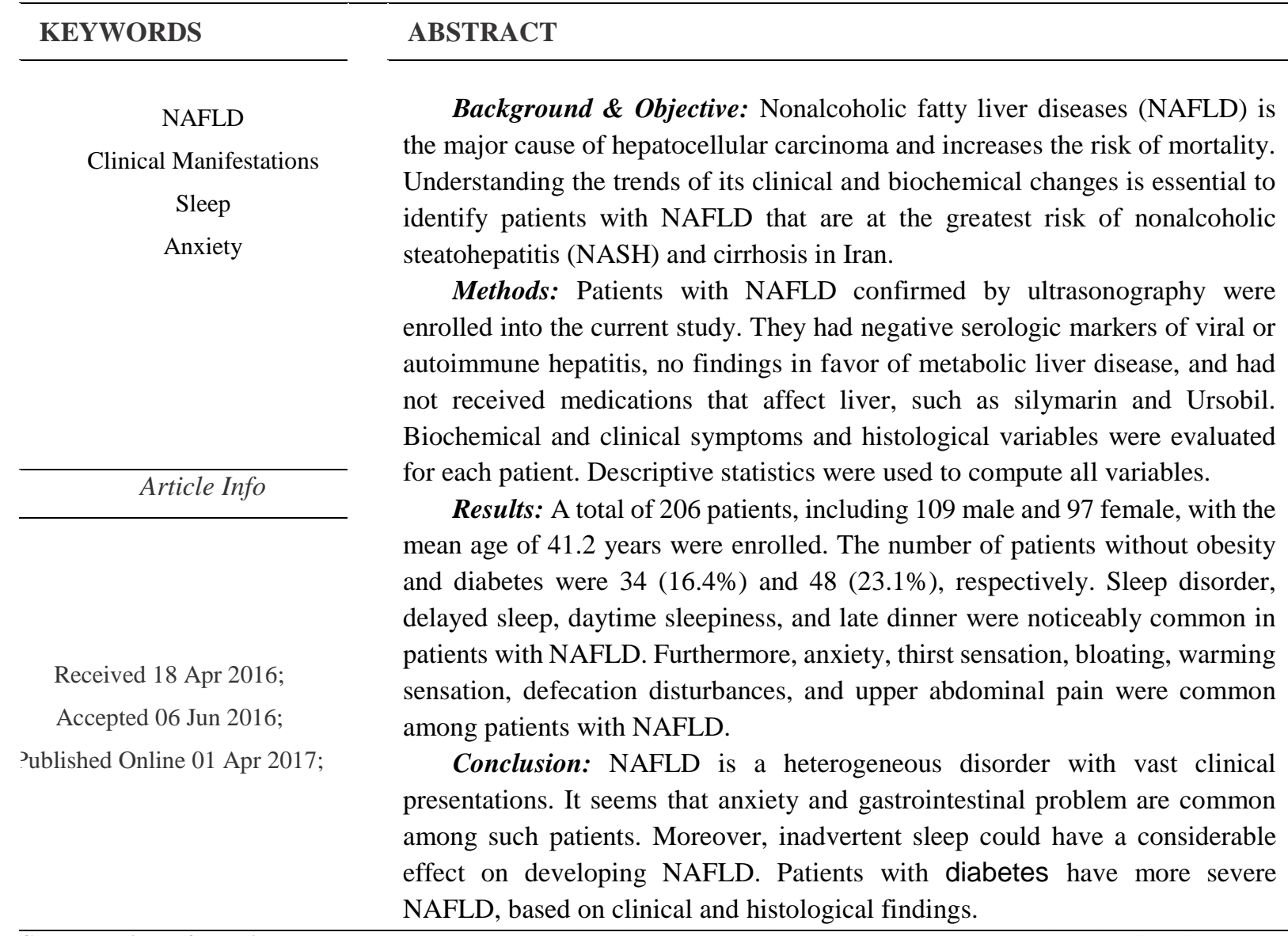

Corresponding Information: Dr. Masoudreza Sohrabi; Gastrointestinal and Liver Disease Research Center, Iran University of Medical Science, Tehran, Iran. Email: sohrab_r@yahoo.com

Copyright $\odot$ 2017, IRANIAN JOURNAL OF PATHOLOGY. This is an open-access article distributed under the terms of the Creative Commons Attribution-noncommercial 4.0 International License which permits copy and redistribute the material just in noncommercial usages, provided the original work is properly cited.

\section{Introduction}

Non alcoholic steatohepatitis (NASH) is part of a broad range of common, chronic, and progressive nonalcoholic fatty liver disease (NAFLD). NAFLD is a clinical term indicating the deposition and accumulation of fat in liver. More than $5 \%$ of liver weight has hepatotoxic effects and could cause liver damage. The term NASH was introduced for the first time by
Ludwig in 1980 for the females with obesity, without history of high intake of alcoholic beverages (1). Although NAFLD is defined as a benign condition, many studies confirmed the reverse cases $(2,3)$.

NAFLD is a complex metabolic condition and has been increasingly recognized as a major cause of liver related morbidity and mortality 
with both lifestyle and genetic risk factors. The disorder has a broad histological spectrum from simple fatty liver to a progressive hepatic injury condition, called NASH. Those who suffer of NASH are prone to a progressively advanced liver fibrosis in an almost short time (4-6). It is reported that $10 \%-35 \%$ of general population have NAFLD (7). The prevalence of NAFLD and its associated risk factors may vary in different geographical regions. Population-based studies on the prevalence of NAFLD and its risk factors in the Iranian population are insufficient. The prevalence of NAFLD and NASH in Iranians varies from $2.9 \%$ to $7.1 \%$ in general population and $55.8 \%$ in patients with type 2 diabetes mellitus (8-10).

It is accepted that NAFLD is a heterogeneous disease with a variety of pathogenic pathways; therefore, It is expected that NAFLD/NASH to have different clinical manifestations. It is also mentioned in traditional medicine that liver diseases might cause different symptoms and complaints, which some of them are not related to liver disease. In fact, there is no specific symptom of NASH that reflect the advanced situation of the patients $(4,9)$. Therefore, the current study aimed at identifying the clinical manifestations of patients with NASH. Some noninvasive predictive scores to predict of advanced fibrosis were also introduced in the current study that was not appropriate for all patients.

\section{Material and Methods \\ Patients}

In a cross sectional study that was conducted from March 2013 to December 2015. Cases were selected from patients referred to liver clinic of the Gastrointestinal and Liver Disease Research Center at Firoozgar Hospital, Tehran, Iran.

The current study included patients aged 18 and over with no history of liver surgery, bariatric surgery, and medications which affect liver such as silymarin, Ursobil, or statin. Patients with other contributory causes of liver disease such as chronic hepatitis B and C, hemochromatosis, autoimmune hepatitis, and the Wilson disease were excluded. NAFLD was defined as reporting fatty liver in ultrasonographic evaluations without other hepatopathies.

\section{Clinical and demographic data collection}

The patients were interviewed and examined by 2 expert gastroenterologists. A questionnaire, including demographic and anthropometric data, physical examinations, and laboratory data was completed for each patient.

Weight was measured to the nearest $100 \mathrm{~g}$ with a scale in light clothing without shoes. Their heights were also measured by stadiometer to the nearest $0.5 \mathrm{~cm}$. The body mass index (BMI) was calculated according to weight $(\mathrm{Kg})$ divided by the square of height (meters). Waist circumflex (WC) was measured at midway between the uppermost border of the iliac crest and the lower border of the costal margin (rib cage).

The quality and quantity of sleep were also asked from the patients. The quality of sleep was evaluated and scored between 0 and 10 , in which $<3=$ bad, 3 to $5=$ not good, 6 to $8=$ good, and 9to $10=$ very good. In this context, the falling asleep time less than 15 minutes, staying asleep without medication no obvious cause of sleep interruptions such as sleepwalking, apnea or night terrors, no feels of light sleep, fragmented or unrefreshing sleep, and sleeping during 10:00 PM to 4:00 AM were considered. The quantity of sleep was defined as the hours of sleeping during the night. The intensity of gastrointestinal symptoms, including abdominal distention and bloating, were evaluated and scored from 0 to 4 , in which $0=$ absent, $1=$ mild, $2=$ moderate, $3=$ severe, and $4=$ intolerable.

Liver function tests including, alkaline phosphatase (ALP), serum albumin, aspartate aminotransferase (AST), bilirubin, alanine aminotransferase (ALT), platelet count, international normalized ratio (INR), total cholesterol (Chol), triglycerides (TGs), highdensity lipoprotein (HDL) cholesterol, lowdensity lipoprotein (LDL) cholesterol, and hemoglobin A1c (HbAlc) were assayed by central laboratory of Firouzgar Hospital. The presence of diabetes mellitus (DM) and hypertension were defined based on American Diabetes Association (ADA) (11) and the Joint 
National Committee (JNC) criteria (12). Blood pressure was measured in 3 positions (prone, setting, and standing). Insulin resistance was assessed with homeostatic model assessmentinsulin resistance (HOMA-IR) based on the following formula: [fasting glucose $(\mathrm{mg} / \mathrm{dL}) \times$ insulin $(\mu \mathrm{U} / \mathrm{mL})$ ] divided by 405 .

\section{Statistical analysis}

The data were analyzed by SPSS software for windows (IBM-SPSS, version 20.0 Chicago, IL, USA). Descriptive statistics was employed to measure all variables; data were reported as means \pm standard deviation (SD) for continuous variables or frequencies, and percentages for categorical variables.

\section{Ethics Approval}

This study protocol was approved by the Ethics Committee of Iran University of Medical Sciences, Tehran, Iran, with ID number: 93038626182 in accordance with the declaration of Helsinki. The procedure was explained to all the participants and a signed written informed consent forms was obtain.

\section{Results}

During the intervention, 206 patients were enrolled into the study. The mean $\pm \mathrm{SD}$ age of the cases was $41.2 \pm 8.3$ years, and $109(52.7 \%)$ cases were male. The mean BMI was $31 \pm 1.5$; also, 34 patients $(16.4 \%)$ had not obesity and $48(23.1 \%)$ had diabetes mellitus. The basic characteristics of the patients are summarized in Table 1 .

NAFLD, nonalcoholic fatty liver disease; FBS, fasting blood sugar; ALT, alanine aminotransferase; AST, aspartateaminotransferase; HOMA-IR, homeostatic model assessmentinsulin resistance

Regarding the clinical presentations, the most common symptoms were upper abdominal pain, fatigue, thirst, and anxiety. The common clinical manifestations are illustrated in Table 2. Also, many of the patients had late onset of sleeping along with late dinner (60.2\%).
Table 1. The Basic Characteristics of Patients With NAFLD

\begin{tabular}{|c|c|}
\hline Variables & $\begin{array}{c}\text { NAFLD } \\
\text { Total }=206\end{array}$ \\
\hline Age (year) Mean \pm SD & $41.2 \pm 8.3$ \\
\hline Male( n) & 109 \\
\hline BMI (kg/m2) & $31 \pm 1.5$ \\
\hline Waist Circumference $(\mathrm{cm})$ mean \pm SD & $106 \pm 10$ \\
\hline FBS $(\mathrm{mg} / \mathrm{dL})$ mean \pm SD & $111.2 \pm 30$ \\
\hline Diabetes $(\%)$ & 23.1 \\
\hline Hypertension (\%) & 26.0 \\
\hline Triglyceride $(\mathrm{mg} / \mathrm{dL})$ mean $\pm \mathrm{SD}$ & $215 \pm 28$ \\
\hline Total cholesterol $(\mathrm{mg} / \mathrm{dL})$ mean $\pm \mathrm{SD}$ & $207 \pm 30$ \\
\hline Hypertriglyceridemia(>200 mg/dL), \% & 44.4 \\
\hline Hyper cholostremia (>200 mg/dL), \% & 42.5 \\
\hline High-density lipoprotein, $(\mathrm{mg} / \mathrm{dL})$ mean \pm SD & $48 \pm 30$ \\
\hline Low-density lipoprotein, $(\mathrm{mg} / \mathrm{dL})$ mean $\pm \mathrm{SD}$ & $70 \pm 39$ \\
\hline Systolic blood pressure $(\mathrm{mmHg})$ mean $\pm \mathrm{SD}$ & $125.2 \pm 17$ \\
\hline Diastolic blood pressure $(\mathrm{mmHg})$ mean $\pm \mathrm{SD}$ & $83.8 \pm 14$ \\
\hline ALT $(\mathrm{U} / \mathrm{L})$ mean \pm SD & $65.0 \pm 32$ \\
\hline $\mathrm{AST}(\mathrm{U} / \mathrm{L})$ mean $\pm \mathrm{SD}$ & $64 \pm 46$ \\
\hline Bilirubin total $(\mathrm{mg} / \mathrm{dl})$ mean \pm SD & $0.9 \pm 0.4$ \\
\hline Insulin level $(\mu \mathrm{IU} / \mathrm{ml})$ mean $\pm \mathrm{SD}$ & $20.18 \pm 20$ \\
\hline Total Albumin $(\mathrm{g} / \mathrm{dl})$ mean \pm SD & $4.2 \pm 0.4$ \\
\hline HOMA-IR index mean \pm SD & $6.0 \pm 7.9$ \\
\hline
\end{tabular}

Table 2. Clinical Manifestations of Patients With NAFLD

\begin{tabular}{|c|c|}
\hline Variables & $\begin{array}{l}\text { NAFLD } \\
\text { Total N }(\%)\end{array}$ \\
\hline Upper abdominal pain & $77(37.4)$ \\
\hline Morning heaviness & $144(69.9)$ \\
\hline Sleep onset after midnight & $130(63.1)$ \\
\hline \multicolumn{2}{|l|}{ Quality of sleep } \\
\hline Very Good & $51(24.7)$ \\
\hline Good & $90(43.7)$ \\
\hline Not Good & $49(23.8)$ \\
\hline Bad & $16(7.7)$ \\
\hline Sleep duration $\leq 6 \mathrm{~h}$ & $25(12.3)$ \\
\hline Time to falling asleep ( $\leq 10 \mathrm{~min})$ & $66(32.0)$ \\
\hline \multicolumn{2}{|l|}{ Sleepiness during day } \\
\hline No & $81(39.3)$ \\
\hline Less than $60 \mathrm{~min}$ & $78(37.8)$ \\
\hline More than $60 \mathrm{~min}$ & $47(22.8)$ \\
\hline Extra ear sound & $70(34.0)$ \\
\hline Nausea & $28(13.6)$ \\
\hline Headache & $90(43.7)$ \\
\hline Decrease of appetite & $56(27.2)$ \\
\hline Thirsty & $179(86.89)$ \\
\hline Degrees of anxiety & $181(87.8)$ \\
\hline \multicolumn{2}{|l|}{ Bloating } \\
\hline Absent & $51(26.2)$ \\
\hline Mild & $39(18.9)$ \\
\hline Moderate & $64(31.6)$ \\
\hline Sever & $41(19.9)$ \\
\hline Disguise & $50(24.3)$ \\
\hline Warming sensation & $130(63.1)$ \\
\hline Palpitation & $59(28.6)$ \\
\hline
\end{tabular}




\section{Discussion}

NAFLD is defined as a condition where $\geq 5 \%$ to $10 \%$ of hepatocytes exhibit macroscopic steatosis by light microscopy in the absence of other etiologies of liver disease. NAFLD is one of the most common causes of chronic liver disease. The results of the current study showed how the clinical symptoms of NAFLD differ among patients. The severity of clinical and biochemical NAFLD presentations is under investigation $(13,14)$. Based on the previous studies, most subjects with NAFLD were asymptomatic and patients were usually diagnosed during a general checkup, when serum level of liver enzymes was found abnormal ( 9 , 14). On the other hand, the problem of a group of patients was detected during a liver imaging assessment and, then, a consequent medical consultation revealed the symptoms that could be associated with the NAFLD $(2,7,15)$.

Regarding the symptoms, although the patients are usually nonspecific, fatigue is the common symptom. However in clinical practice, the study faced many patients with vast clinical complaints. On the other hand if human is considered as a whole; hence, manifestation of liver disease may present differently. Therefore, concerning the fact the patients were examined, which resulted in interesting clinical findings. In the present study, anxiety, thirst, feeling of changing temperature, and bloating were the most common complaints. Disguise and upper abdominal pain, particularly in the left upper quadrant, were also a common complaint. The upper abdominal pain may have sharp or dull quality. The complaint of frequent bloating, disguise, thirst, and headaches were almost present recently, before medical consultation and were usually treated as dyspepsia and reflux disease. Sleep disorder and late onset of sleeping were noticeable.

Recently, many attempts are made to evaluate the effects of sleep quality and quantity in the development, and progression of inflammation and chronic diseases . This is almost a new issue in NAFLD, but it has a long history in the Iranian traditional medicine; as it is indicated in major reference books. Based on the Iranian traditional medicine, the best time to sleep is 10:00 PM to 4:00 AM, which is almost comparable with solar circadian. In fact, many of the patients in the current study stayed up late at night and woke up late in the morning. Brensmeier et al., reported a case-control study in which short sleep duration, delayed onset, and poor quality of sleep were common among patients with NAFLD. They also confirmed the association of NAFLD with late dinner. The association between sleep disturbances and dinner time needs further studies $(16,17)$. Previous studies also revealed the association between sleep apnea and NAFLD (17-19) .

It is noteworthy that, in the current study the majority of subjects were male. Nevertheless, in many studies females were predominant; while, recent studies revealed the antecedence of male in this condition and the current results were comparable with those of them. This could be related to life style and dietary changes and the fact that males are more susceptible to the same risk factors. In addition, some studies illustrated that stress may be involved in NAFLD progress and males are prone to daily stress $(17,20,21)$. Furthermore, obesity was the most frequent clinical finding and the previous studies estimated that almost $30 \%$ to $100 \%$ of the patients with NAFLD were obese. Several studies substantiated the positive correlation of WC and BMI, with NAFLD and NASH (22) (23). Obesity itself is associated with metabolic syndrome, and sleep apnea and sleep disorders (as the consequence of obesity, which cause chronic fatigue) are all among clinical presentations of NAFLD (20, 21, 24). In addition, WC is considered as an important issue in clinical setting to detect NAFLD. In a recent study, Motamed et al., declared that WC has the same power as fatty liver index (FLI) to diagnose NAFLD $(25,26)$.This factor represents abdominal obesity, which in patients with NAFLD is usually, but not always, higher than normal. Hence, patients with lean body NAFLD/NASH require more attention.

Blood pressure is considered as a manifestation of metabolic syndrome and NASH. In the current study, the mean blood 
pressure was about normal (125/83 $\mathrm{mmHg})$. An exact cannot be offered, but it could be due to the limited number of participants. In former studies, the presence of DM along with other factors, such as higher BMI, hypertension and older age, were associated with severity of NAFLD/NASH (27). In the current study, according to Table 1, the mean age and BMI of the patients with NAFLD were 41 years and 31.4, respectively; the prevalence of DM was $23 \%$, which were comparable with the previous reports (3). In fact, it seems that the age of NAFLD and NASH onset might be reduced, as reported by some studies ( 8 , 28). Several population-based studies, however, revealed the increasing trend of NAFLD and NASH with age $(2,13)$.

In conclusion, NASH could be presented with different clinical manifestation as long time before the diagnosis .Although fatigue is a common complaint of patients, the consultant must consider other related symptoms. Furthermore, it seems that NASH is not actually a female prominent condition. Moreover, poor quality of sleep and sleep disorder could be considered as the risk factors that should be investigated.

\section{Acknowledgements}

The current research was supported by Iran University of Medical Sciences. Authors thank the personnel of Firouzgar Hospital who provided insight, and expertise that greatly assisted the research.

\section{Conflict of Interest Statement}

The authors declared no conflict of interest exists.

\section{References}

1.Brunt EM. Pathology of fatty liver disease. Mod Pathol. 0000;20(1s):S40-S8.

2.Festi D, Schiumerini R, Marzi L, Di Biase AR, Mandolesi D, Montrone L, et al. Review article: the diagnosis of non-alcoholic fatty liver disease -- availability and accuracy of noninvasive methods. Alimentary pharmacology \& therapeutics. 2013;37(4):392-400.

3.Goh GB, Pagadala MR, Dasarathy J, Unalp-Arida A, Sargent R, Hawkins C, et al. Clinical spectrum of non-alcoholic fatty liver disease in diabetic and non-diabetic patients. BBA clinical. 2015;3:141-5.

4.Chalasani N, Younossi Z, Lavine JE, Diehl AM, Brunt EM, Cusi K, et al. The diagnosis and management of non-alcoholic fatty liver disease: practice Guideline by the American Association for the Study of Liver Diseases, American College of Gastroenterology, and the American Gastroenterological Association. Hepatology. 2012;55(6):2005-23.

5.Musso G, Gambino R, Cassader M, Pagano G. Meta-analysis: natural history of nonalcoholic fatty liver disease (NAFLD) and diagnostic accuracy of non-invasive tests for liver disease severity. Ann Med. 2011;43(8):617-49.

6.Younossi ZM, Stepanova M, Rafiq N, Makhlouf H, Younoszai Z, Agrawal R, et al. Pathologic criteria for nonalcoholic steatohepatitis: interprotocol agreement and ability to predict liver-related mortality. Hepatology. 2011;53(6):1874-82.

7.Alavian SM, Mohammad-Alizadeh AH, Esna-Ashari F, Ardalan G, Hajarizadeh B. Nonalcoholic fatty liver disease prevalence among school-aged children and adolescents in Iran and its association with biochemical and anthropometric measures. Liver Int. 2009;29(2):159-63.

8.Amirkalali B, Poustchi H, Keyvani $\mathrm{H}$, Khansari MR, Ajdarkosh H, Maadi M, et al. Prevalence of Non-Alcoholic Fatty Liver 
Disease and Its Predictors in North of Iran. Iranian journal of public health. 2014;43(9):1275-83.

9.Bahrami H, Daryani NE, Mirmomen S, Kamangar F, Haghpanah B, Djalili M. Clinical and histological features of nonalcoholic steatohepatitis in Iranian patients. BMC gastroenterology. 2003;3:27.

10.Wang $\mathrm{Y}$, Zeng $\mathrm{Y}$, Lin $\mathrm{C}$, Chen $\mathrm{Z}$. Hypertension and Nonalcoholic Fatty Liver Disease Proven by Transient Elastography. Hepatol Res. 2016.

11.Diagnosis and classification of diabetes mellitus. Diabetes care. 2013;36 Suppl 1:S6774.

12.Chobanian AV, Bakris GL, Black HR, Cushman WC, Green LA, Izzo JL, Jr., et al. Seventh report of the Joint National Committee on Prevention, Detection, Evaluation, and Treatment of High Blood Pressure. Hypertension. 2003;42(6):1206-52.

13.Bellentani S, Scaglioni F, Marino M, Bedogni G. Epidemiology of non-alcoholic fatty liver disease. Digestive diseases (Basel, Switzerland). 2010;28(1):155-61.

14.Sugimoto K, Takei Y. Clinicopathological features of non-alcoholic fatty liver disease. Hepatol Res. 2011;41(10):911-20.

15.Lazebnik LB, Radchenko VG, Golovanova EV, Zvenigorodskaya LA, Konev YV, Seliverstov PV, et al. [NONALCOHOLIC FATTY LIVER DISEASE: DIAGNOSTIC, SYMPTOMS, TREATMENT. GUIDELINES WERE APPROVED BY THE XV GASTROENTEROLOGICAL SCIENTIFIC SOCIETY OF RUSSIA IN 2015]. Eksp Klin Gastroenterol. 2015(7):85-96.

16.McPherson S, Stewart SF, Henderson E, Burt AD, Day CP. Simple non-invasive fibrosis scoring systems can reliably exclude advanced fibrosis in patients with non-alcoholic fatty liver disease. Gut. 2010;59(9):1265-9.
17.Bernsmeier C, Weisskopf DM, Pflueger MO, Mosimann J, Campana B, Terracciano L, et al. Sleep Disruption and Daytime Sleepiness Correlating with Disease Severity and Insulin Resistance in Non-Alcoholic Fatty Liver Disease: A Comparison with Healthy Controls. PloS one. 2015;10(11):e0143293.

18.Petta S, Marrone O, Torres D, Buttacavoli M, Camma C, Di Marco V, et al. Obstructive Sleep Apnea Is Associated with Liver Damage and Atherosclerosis in Patients with NonAlcoholic Fatty Liver Disease. PloS one. 2015;10(12):e0142210.

19.Benotti P, Wood GC, Argyropoulos G, Pack A, Keenan BT, Gao X, et al. The impact of obstructive sleep apnea on nonalcoholic fatty liver disease in patients with severe obesity. Obesity (Silver Spring, Md). 2016.

20.Kim CW, Yun KE, Jung HS, Chang Y, Choi ES, Kwon MJ, et al. Sleep duration and quality in relation to non-alcoholic fatty liver disease in middle-aged workers and their spouses. J Hepatol. 2013;59(2):351-7.

21.Newton JL, Jones DE, Henderson E, Kane $\mathrm{L}$, Wilton $\mathrm{K}$, Burt AD, et al. Fatigue in nonalcoholic fatty liver disease (NAFLD) is significant and associates with inactivity and excessive daytime sleepiness but not with liver disease severity or insulin resistance. Gut. 2008;57(6):807-13.

22.Jakobsen MU, Berentzen T, Sorensen TI, Overvad K. Abdominal obesity and fatty liver. Epidemiologic reviews. 2007;29:77-87.

23.Williams CD, Stengel J, Asike MI, Torres DM, Shaw J, Contreras M, et al. Prevalence of nonalcoholic fatty liver disease and nonalcoholic steatohepatitis among a largely middle-aged population utilizing ultrasound and liver biopsy: a prospective study. Gastroenterology. 2011;140(1):124-31.

24.Newton JL. Systemic symptoms in nonalcoholic fatty liver disease. Digestive diseases (Basel, Switzerland). 2010;28(1):214-9. 
25.Motamed N, Miresmail SJ, Rabiee B, Keyvani H, Farahani B, Maadi M, et al. Optimal cutoff points for HOMA-IR and QUICKI in the diagnosis of metabolic syndrome and nonalcoholic fatty liver disease: A population based study. Journal of diabetes and its complications. 2016;30(2):269-74.

26.Motamed N, Zamani F, Rabiee B, Saeedian FS, Maadi M, Akhavan-Niaki H, et al. The Best Obesity Indices to Use in a Single Factor Model Indicating Metabolic Syndrome: a Population Based Study. Archives of Iranian medicine. 2016;19(2):110-5.
27. Ekstedt M, Franzen LE, Mathiesen UL, Thorelius L, Holmqvist M, Bodemar G, et al. Long-term follow-up of patients with NAFLD and elevated liver enzymes. Hepatology. 2006;44(4):865-73.

28. Ashtari S, Pourhoseingholi MA, Zali MR. Non-alcohol fatty liver disease in Asia: Prevention and planning. World J Hepatol. 2015;7(13):1788-96.

\section{How to Cite This Article:}

Khoonsari M, Mohammad Hosseini Azar M, Ghavam R, Hatami K, Asobar M, gholami A, et al. Clinical Manifestations and Diagnosis of Non-Alcoholic Fatty Liver Disease. Iran J Pathol. 2017;12(2):99-105. 